\title{
Preparation and characterization of Chicory leaf powder and its application as a nano-native plant sorbent for removal of Acid Blue 25 from aqueous media: isotherm, kinetic and thermodynamic study of the adsorption phenomenon
}

\author{
Maryam Haghighizadeh $^{1} \cdot$ Karim Zare $^{1} \cdot$ Hossein $_{\text {Aghaie }}{ }^{1} \cdot$ Majid Monajjemi $^{1}$
}

Received: 17 August 2019 / Accepted: 31 December 2019 / Published online: 29 January 2020

(c) The Author(s) 2020

\begin{abstract}
In this study, the Chicory leaf powder (CLP) was used as a native adsorbent to eliminate the Acid Blue 25 dye from aqueous media. The prepared native adsorbent was characterized by several techniques including the X-ray powder diffraction (XRD), scanning electron microscopy (SEM), Fourier-transform spectroscopy (FTIR), Brunauer-Emmet-Teller essay (BET), and particle size analyzer (PSA). A collection of experiments was performed to distinguish the optimal conditions and to probe the effects of the different parameters such as initial concentration, contact time, adsorbent dosage, $\mathrm{pH}$ of solution, and temperature on the sorbent capacity. The attained optimal conditions for removal the Acid Blue 25 dye were $\mathrm{pH}=3-4$, contact time $50 \mathrm{~min}$, dosage $0.1 \mathrm{~g}$, and initial concentrations $10(\mathrm{mg} / \mathrm{L})$ at $30^{\circ} \mathrm{C}$. The adsorption data revealed that the adsorption procedure has more match with the Langmuir isotherm than others. The kinetic data were better fitted with the pseudo-second-order pattern with a trusty correlation coefficient. Finally, the thermodynamic parameters illustrated that the adsorption process is exothermal and spontaneous. Based on magnitude of the standard enthalpy change related to the studied adsorption, we may derive that the considered adsorption is physical adsorption.
\end{abstract}

Keywords Adsorption · Chicory leaf powder · Adsorbent · Acid Blue $25 \cdot$ Kinetics $\cdot$ Thermodynamics $\cdot$ Isotherm

\section{Introduction}

Toxicity of dye compounds has been a major problem of human for several years [1]. Dyes are contaminants which are widely consumed in industrial operations such as textile, wood manufacturing, paper mills, and leather. It is necessary that the industrial wastewater be refined before it is discharged into the environment. A number of applied sciences have been developed over years for eliminating dye pollutants from aqueous solutions [2-4], as dyes are significant environmental pollutants and destroy natural eco-systems in particular. One of these methods is the adsorption process. In recent years, numerous studies have been accomplished to remove dyes from eco-systems using diverse adsorbents [5-7]; adsorbents with the superiorities of availability and

Karim Zare

Prof.karimzare@gmail.com; K-zare@srb.ac.ir

1 Department of Chemistry, Science and Research Branch, Islamic Azad University, Tehran, Iran low cost of the processing $[8,9]$. For example, the removal value of congo red by aloe vera leaf shell carried out with the maximum uptake capacity of CR dye by AV-AC was $1850 \mathrm{mg} / \mathrm{g}$ [10]. In another research, the Azollapinnata (AP) and soya bean waste (SBW) adsorbents were used for removing Acid Blue 25 from aqueous solutions [11]. Overall, there are extensive research works on the use of natural adsorbents to remove hazardous dyes to refine eco-systems [12].

In this study, we used Chicory leaf powder (CLP) as a native adsorbent to adsorb Acid Blue 25; it is referred to as CLP hereinafter.

Acid Blue 25 (AB25) belongs to the anthraquinone and anionic dyes class which is the most important dye following azo dyes with chemical formula $\mathrm{C}_{20} \mathrm{H}_{13} \mathrm{~N}_{2} \mathrm{NaO}_{5} \mathrm{~S}$ and molecular mass $416.38(\mathrm{~g} / \mathrm{mol})$. It is generally applied for dying wool, leather, detergents, wood, ink fur, and cosmetics [13].

Chicory plant is in two species; one kind is cultivated, while the other is savage and grows on its own. The main source of Chicory plant is central Europe, the western and central parts of Asia and north Africa, and has a vast 
scattering in different areas of Iran $[14,15]$.The scientific name for this herb is Cichorium intybus and belongs to the category Asteraceae. Chicory has certain amount of vitamins, minerals (such as magnesium, phosphorus, $\mathrm{C}$ vitamin and B group vitamins) and active compounds such as inulin, fats and sesquiterpene lactones. In total, 20 components were identified in the aerial portions of this herb. Some of the chemical compositions are carvacrol $(50.1 \%)$, thymol (13.3\%), cinnamic aldehyde (12.4\%), camphor (4.4\%), linalool (3.9\%) and terpineol $(2.1 \%)[16,17]$. The discrepancy between this research and other studies is the use of a new natural adsorbent, which, in addition to its medicinal attributes, seems to be an eligible herbal adsorbent for adsorbing ionic polluters. In articles [18], the effects of the drug and the adsorption of toxins in the liver were investigated by Chicory plant and its compounds.

The original target of the study is to test the adsorption treatment of Chicory savage powder as adsorbent with respect to Acid Blue 25 [19]. Remember that the technology of adsorption has been widely studied in last years. It is a suitable and effective technology for homemade and industrial wastewater therapy $[20,21]$. The effects of different agents, such as initial concentrations of solution, contact time; $\mathrm{pH}$ values, adsorbent dosage, and temperature were investigated. The thermodynamics and kinetics of Acid Blue 25 adsorption onto the CLP were also studied.

\section{Experimental}

\section{Chemical}

All chemicals applied in this research were made a purchase from Merk Company and were of analytical standard. They were applied without further purification. Acid Blue 25, potassium hydroxide, hydrochloric acid, sodium hydroxide and sodium chloride were also from the same company and sued as received.

\section{Instruments}

The adsorption of Acid Blue 25 in the desired studied solutions was quantified by a UV-Vis 1700 Simadzo model spectrophotometer at wavelength of $597 \mathrm{~nm}$. The UV-Vis spectrophotometer was used to record the solution phase absorption. The measurement of the solutions' $\mathrm{pH}$ was done by A5500 model $\mathrm{pH}$ meter. A Neolab model shaker was used in the batch experiments which was thermostatic orbit incubator. The adsorbent specifications were investigated by X-ray powder diffraction (XRD) and Fourier-transform infrared spectroscopy (FTIR) (varian 1000 Ft-IR Scimitar series). The specific surface area and total pore volume was determined by BET/BJH analyzer. The particle size analyzer
(PSA) was used for the particle size determination. Scanning electron microscopy (SEM) and transmission electron microscopy (TEM) were used for the size determination of CLP.

\section{Preparation of adsorbent}

At first, Chicory leaves were washed and dried in the laboratory and powdered by a milling device. The powder was sieved via a mesh number 100 . Then, $5 \mathrm{~g}$ of CLP was placed in $0.01 \mathrm{M} \mathrm{KOH}$ solution for $15 \mathrm{~h}$, and it was placed on ultrasonic bath for $2 \mathrm{~h}$. Then, the product was filtered and rinsed multiple times with distilled water, and then it was dried about $3 \mathrm{~h}$ at $90^{\circ} \mathrm{C}$ in oven. After heating, the dried powder was put in a desiccator for 1 day. Then, it was gently compressed to turn into a tiny powder [22, 23].

\section{Designing a typical adsorption experiment}

The method of operation of an adsorption experiment is very momentous. In general, the ordinary procedure (batch method) is as follows: an adequate dosage of sorbent (e.g. $0.10 \mathrm{~g}$ ) is mixed with the intended volume of sorbate solution with a investigated concentration (e.g. $50 \mathrm{~mL}$ with concentration of $\left.10 \mathrm{mg} \mathrm{L}^{-1}\right)$. Then, the solution $\mathrm{pH}$ and temperature should be adjusted at the desired values (e.g. $3-4$ and $30^{\circ} \mathrm{C}$, respectively). The obtained mixture should be stirred under the constant $\mathrm{pH}$ and temperature for suitable time interval (e.g. $50 \mathrm{~min}$ ). The final mixture should be filtered, using a filter paper with a high quality. Finally, the concentration of the filtered solution (the obtained solution upon filtration) must be determined by an effective method, including spectrophotometric measurement, atomic absorption method, etc. In addition, the initial concentration should also be measured with the same instrument for promoting the measurement precision $[24,25]$.

The level, mg, of the adsorbed dye per gram of CLP at equilibrium, $q_{e}(\mathrm{mg} / \mathrm{g})$ or adsorption capacity, and the adsorption percentage, $(\% \mathrm{~A})$, were computed applying the following equations $[1,26]$ :

$q_{e}=\frac{\left(C_{0}-C_{e}\right) V}{m}$

$\% A=\frac{C_{0}-C_{e}}{C_{0}} \times 100$,

where $C_{0}(\mathrm{mg} / \mathrm{L})$ is the initial concentration and $C_{e}(\mathrm{mg} / \mathrm{L})$ signified the equilibrium concentration of dye. $m$ and $V$ represent the mass of the sorbent ( $\mathrm{g}$ ) and the volume of the test solution (L), respectively. It is worthwhile to note that \% A and $q$ is a reliable criterion for evaluating the efficiency of an adsorption process. 
Here, it should be noted that, several parameters including initial concentration of sorbate, $\mathrm{pH}$ solution, dosage of sorbent, temperature, contact time and some other conditions affect seriously the adsorption capacity of any adsorption process.

Therefore, determination of the optimum value of each mentioned parameter must firstly evaluate a discussed.

\section{Results and discussion}

\section{Characterization of Chicory leaf powder}

The chemical combination of CLP was determined by other researchers $[16,17]$. In this study, some other characterizations were done. The X-ray diffraction pattern of the prepared CLP (Fig. 1) has no sharp peak and revealed that the prepared adsorbent is an amorphous material. Figure $2 \mathrm{a}$ and $b$ displays the two images of the SEM and TEM of CLP indicating that the prepared CLP has a good quality as an adsorbent. The TEM image (Fig. 2b) indicates the gauge of the most native adsorbent particles was near $100 \mathrm{~nm}$ or somewhat smaller or larger.

Figure 3 displays the FTIR spectrum of CLP. The peaks at $2900 \mathrm{~cm}^{-1}$ and $3000-3700 \mathrm{~cm}^{-1}$ are related to the $\mathrm{C}-\mathrm{H}\left(\mathrm{sp}^{2}\right)$ and $\mathrm{O}-\mathrm{H}$ functional groups, respectively, while $1600-1680 \mathrm{~cm}^{-1}$ represents $\mathrm{C}=\mathrm{C}$ bond. The peak at around $1700 \mathrm{~cm}^{-1}$ is associated with $\mathrm{C}=\mathrm{O}$ stretch. The weak peak at $1425 \mathrm{~cm}^{-1}$ confirms a $\mathrm{C}-\mathrm{C}$ aromatic bond. Also, there are several strong peaks at $1050-1255 \mathrm{~cm}^{-1}$ which are $\mathrm{C}-\mathrm{O}-\mathrm{C}$ stretching functional group and the last broad peak indicates $\mathrm{C}-\mathrm{Br}$ at $580 \mathrm{~cm}^{-1}$. From these peaks, we can conclude many organic and inorganic compounds

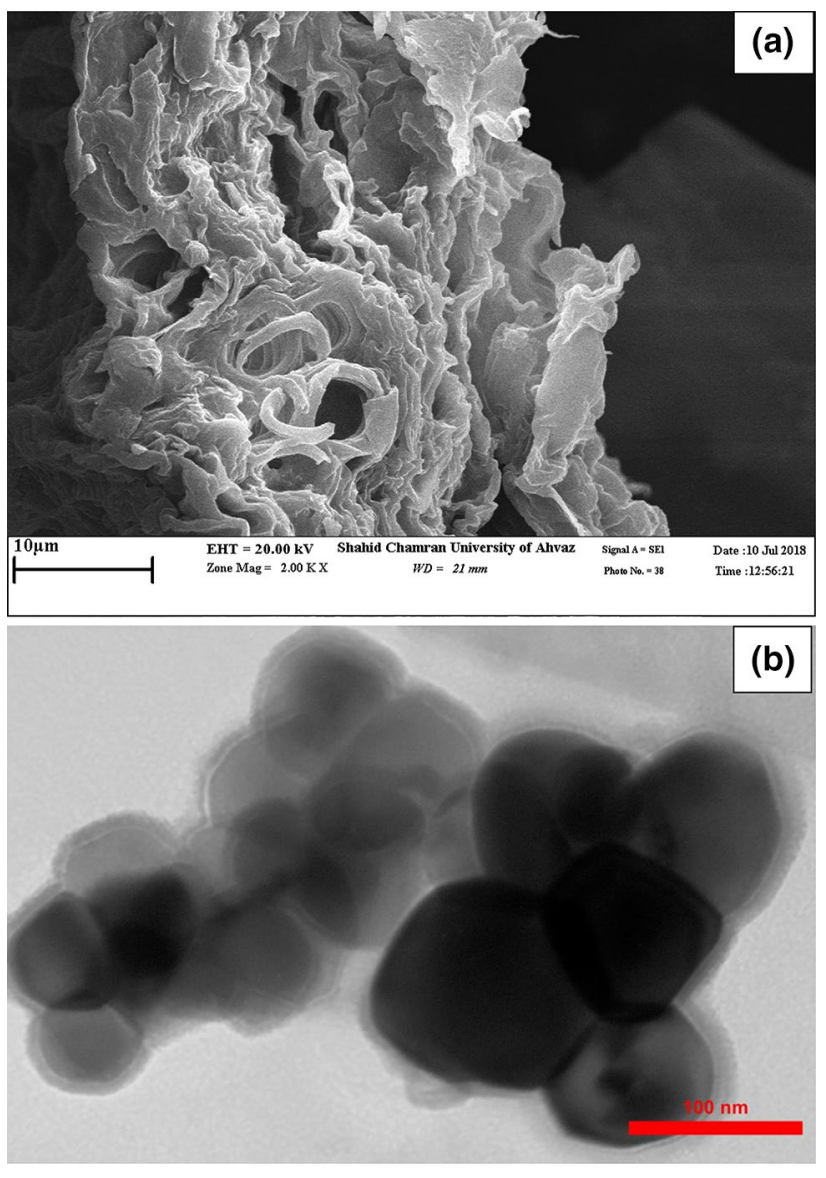

Fig. 2 The SEM image (a) and TEM image (b) of CLP
Fig. 1 X-ray powder diffraction (XRD) of CLP

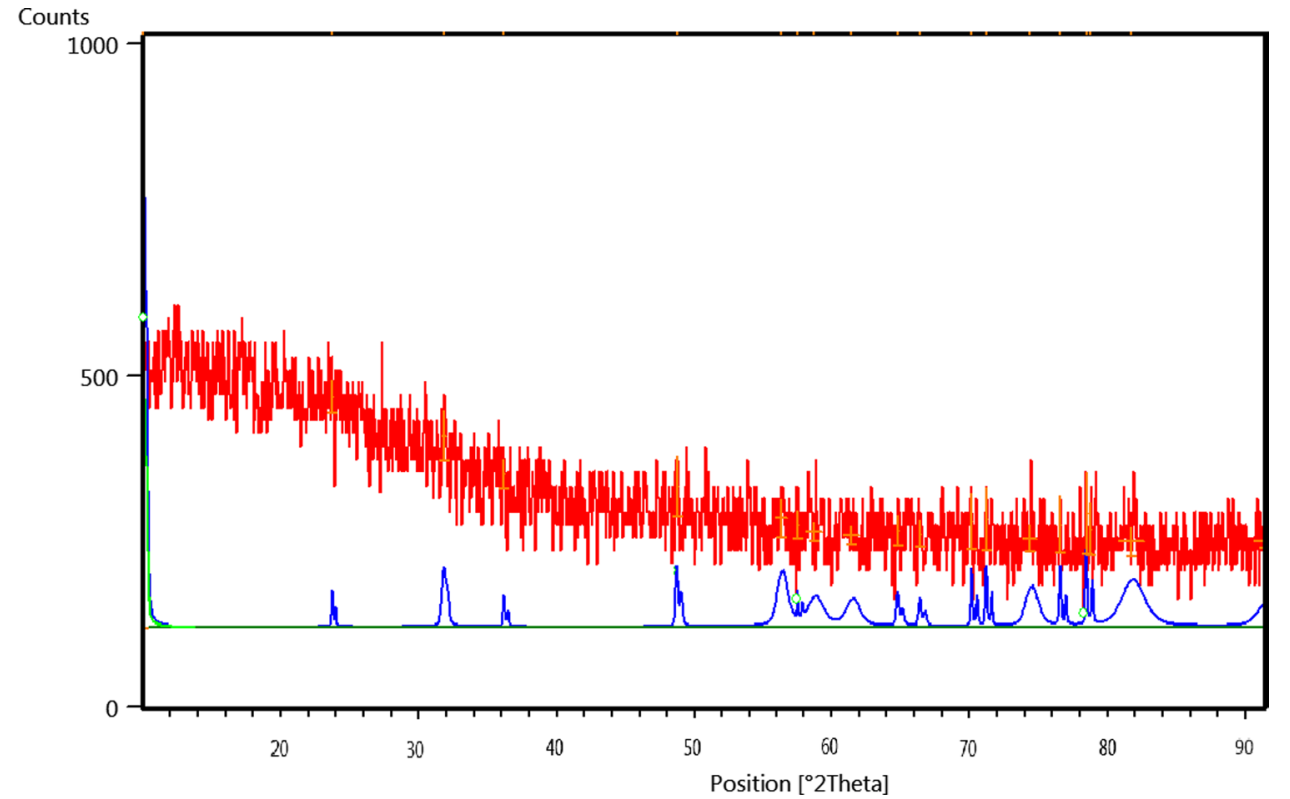




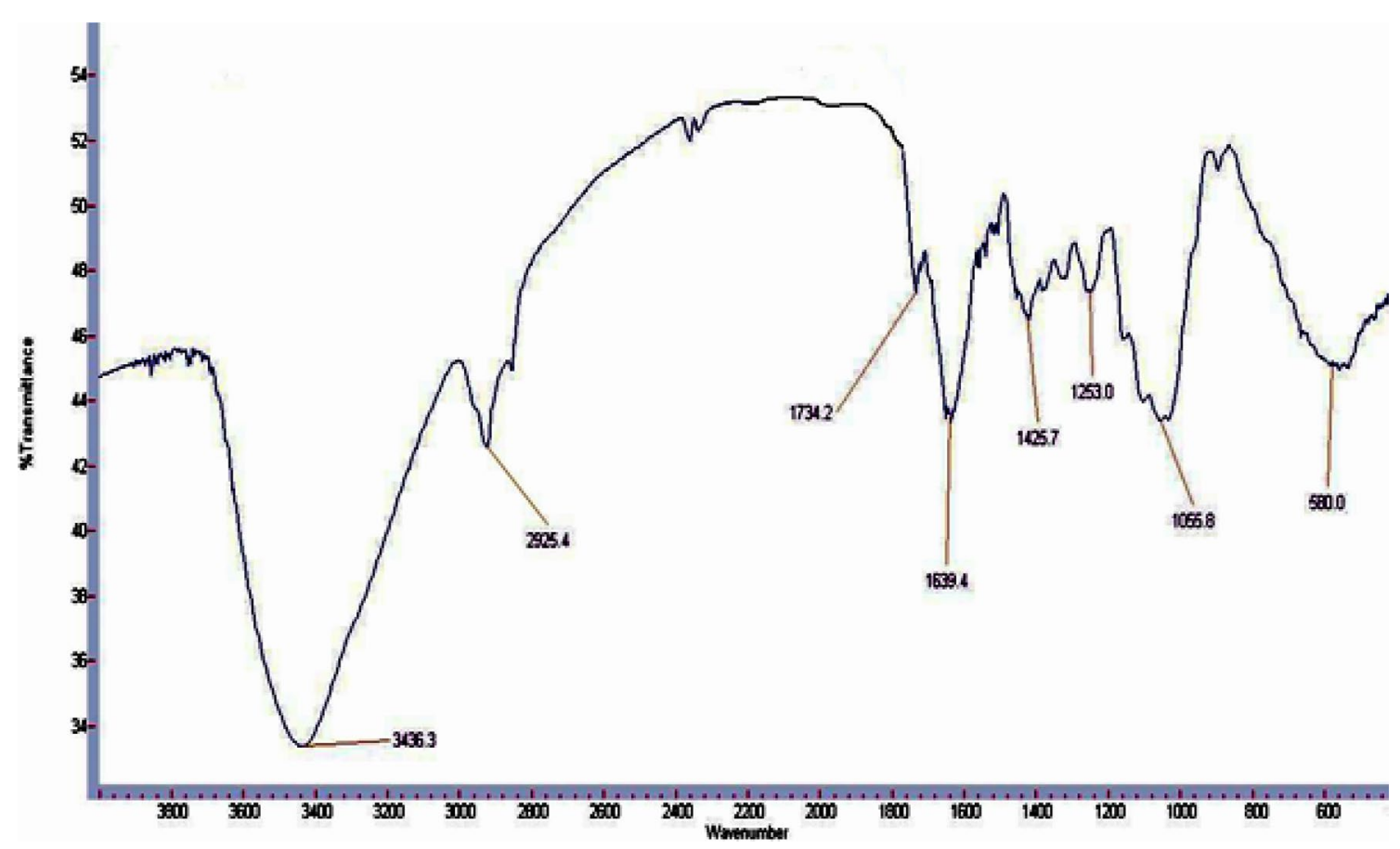

Fig. 3 FTIR spectrum of Chicory leaf powder (CLP)

are found in CLP [16]. The obtained specific surface area of CLP by BET essay was $6.09 \mathrm{~m}^{2} / \mathrm{g}$ (at ambient pressure: $1 \mathrm{~atm}$ and detector temperature: $100{ }^{\circ} \mathrm{C}$ ), which is relatively larger than that of flax, cotton and cellulose fibers. Our value is near to the values reported in $[27,28]$ and the total pore volume of CLP was $0.0692 \mathrm{~m}^{3} / \mathrm{g}$.

Charge essay: to investigate the CLP electrical behavior, we performed a simple experiment by an assembly consisting of two electrodes in a mixture of CLP and distilled water plus a battery in the electrical circuit. We found that the CLP particles do not migrate toward any electric charge. The $\mathrm{pH}$ of zero point charge $\left(\mathrm{pH}_{\mathrm{pzc}}\right)$ of the adsorbent was determined by the salt addition method applying $0.01 \mathrm{~mol} \mathrm{~L}^{-1} \mathrm{NaCl}$ solutions [29]. The $\mathrm{pH}$ of the $\mathrm{NaCl}$ solutions was adjusted with $0.1 \mathrm{~mol} \mathrm{~L}^{-1} \mathrm{HCl}$ and $\mathrm{NaOH}$ to initial $\mathrm{pH}$ of $2.0-10.0$. The $\mathrm{pH}$ was measured using a $\mathrm{pH}$ meter. Specifically, $0.02 \mathrm{~g}$ of the adsorbent was added to $20 \mathrm{~mL}$ of $\mathrm{pH}$-adjusted $\mathrm{NaCl}$ and shaked for $24 \mathrm{~h}$ at $250 \mathrm{rpm}$ applying an orbital shaker and the ultimate $\mathrm{pH}$ was measured. The final $\mathrm{pH}$ versus initial $\mathrm{pH}$ was plotted to determine the $\mathrm{pH}_{\mathrm{pzc}}$. The $\mathrm{pH}_{\mathrm{pzc}}$ of CLP was found to be at 7.1.

In addition, the particle size analyzer experiment was also performed where the results demonstrated that the size of the most native adsorbent particles was near $100 \mathrm{~nm}$ or somewhat larger. The intensity distribution graph (Fig. 4) shows the particle size of Chicory leaf powder (CLP).

\section{The effect of adsorbent dosage}

Sufficient levels of adsorbent are a main parameter to be considered, since it specifies the number of free adsorption sites for a given initial concentration of the dye [30]. The experiments were accomplished at the normal $\mathrm{pH}$ (5.5) of the dye solution, the initial concentration $30 \mathrm{mg} / \mathrm{L}$, and the contact time $30 \mathrm{~min}$ at $25{ }^{\circ} \mathrm{C}$. The quantity of CLP dosage was altered from 10 to $100 \mathrm{mg}$. Figure 5a demonstrates the graph of CLP dosage versus the adsorption percentage of the Acid Blue 25 dye.

Based on Fig. 5a, with elevation of the adsorbent dosage (or adsorbent' mass), the adsorption percentage increased, and the optimum dosage was chosen $100 \mathrm{mg}$.

\section{The effect of temperature}

The effect of temperature on the sorption of Acid Blue 25 onto CLP was tested at $25^{\circ} \mathrm{C}, 30^{\circ} \mathrm{C}, 40^{\circ} \mathrm{C}$, and $50^{\circ} \mathrm{C}$, while the other parameters including the initial concentration, contact time, and solution $\mathrm{pH}$ were $30 \mathrm{mg} / \mathrm{L}, 30 \mathrm{~min}$ and normal $\mathrm{pH}$, respectively. As Fig. 5b illustrates, the removing percentage of the Acid Blue 25 dye increased gradually from 25 to $30^{\circ} \mathrm{C}$ and then diminished with increment of temperature. The reason is that by raising the temperature, dye molecules 


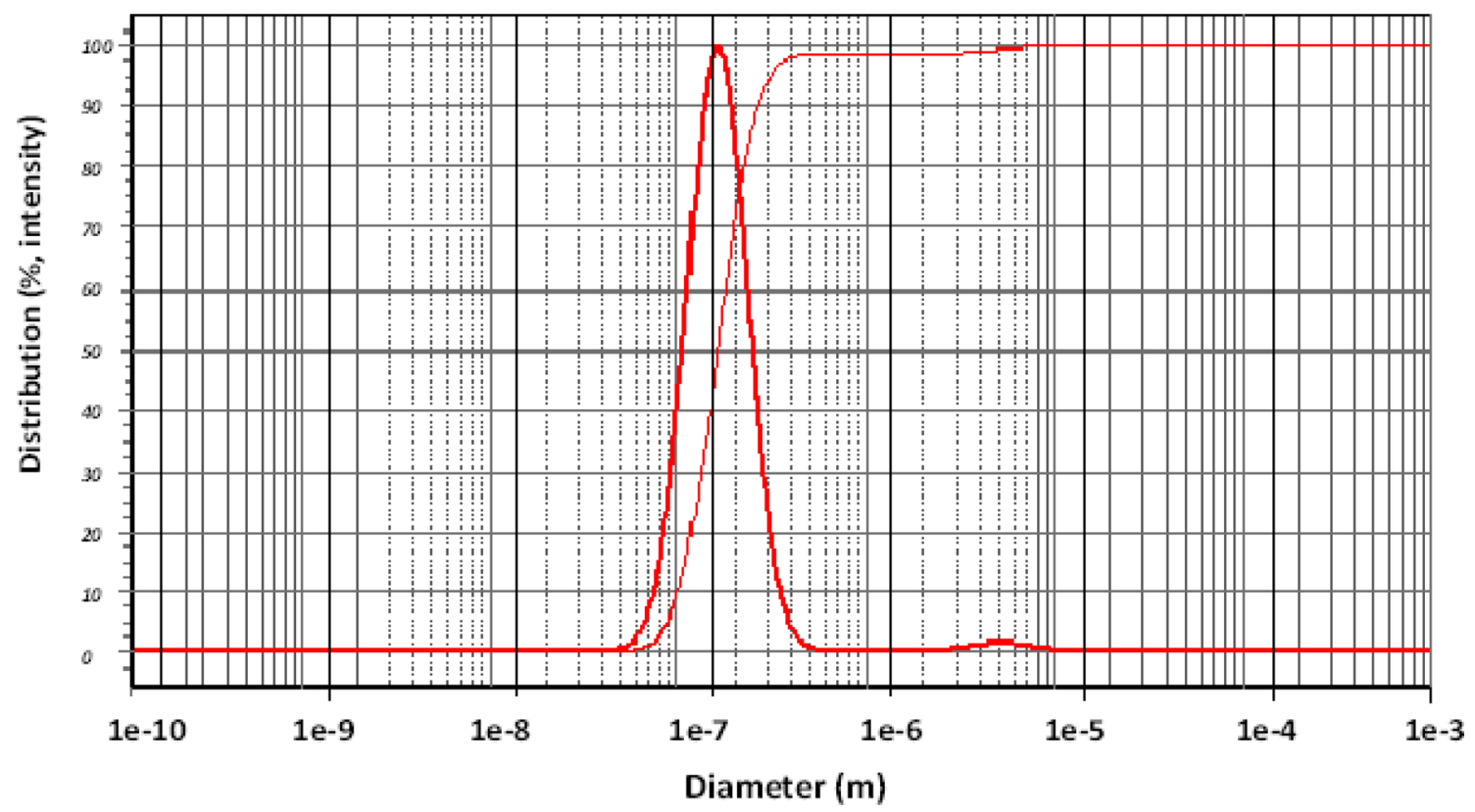

Fig. 4 The intensity distribution graph of the particle size of Chicory leaf powder (CLP)

Fig. 5 The graph of examination of adsorbent dosage (a), the graph of investigation of temperature (b), the graph of inspection of contact time (c), and the graph of studying $\mathrm{pH}$ (d) versus the Acid Blue 25 dye adsorption percentage (a)

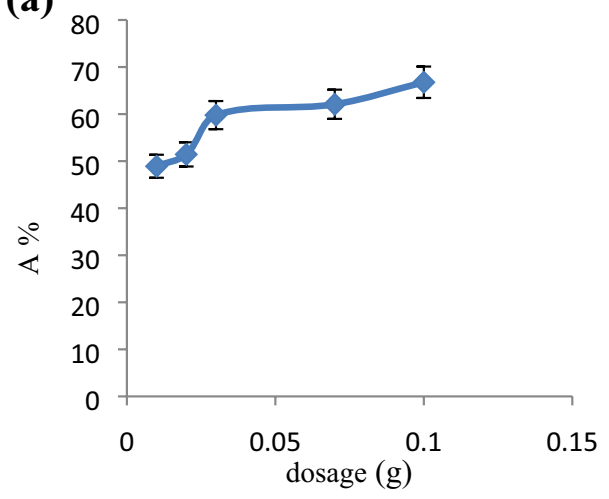

(c)

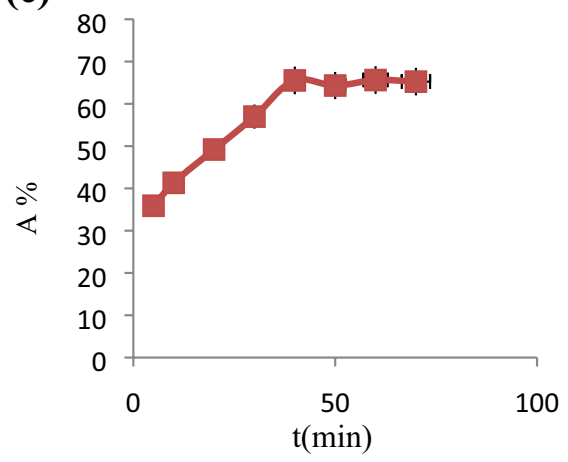

(b)

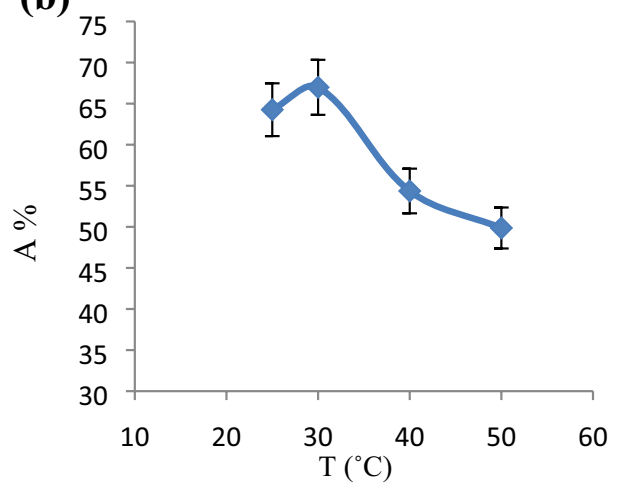

(d)

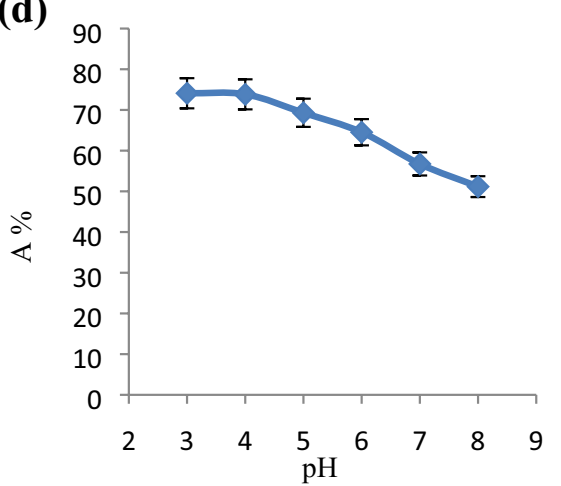

move more vigorously, and the adsorption capacity is also increased; however, at a higher temperature, desorption may take a prevailing role [31]. The optimum temperature may be chosen as $30^{\circ} \mathrm{C}$. 


\section{The effect of contact time}

The equilibrium contact time is one of the most basic parameters of the adsorption procedure. The effect of contact time on the adsorption procedure was investigated [32, 33]. Every experiment was carried out using $100 \mathrm{mg}$ of adsorbent at normal $\mathrm{pH}$ (5.5) of the dye solution and at temperature $30{ }^{\circ} \mathrm{C}$. The initial concentration of Acid Blue 25 solution was $30(\mathrm{mg} / \mathrm{L})$. According to Fig. 5c, the adsorbent displays an imperceptible growth for the dye adsorption, as the contact time increased. Note that beyond $50 \mathrm{~min}$, there is no considerable growth in the dye uptake. At first, the number of adsorbent sites of available is high, so the adsorption percentage increases gradually, as the time passage the adsorbent sites is occupied by a great number of the molecules of Acid Blue 25, and the adsorption rate does not change much and remains constant. Hence, $50 \mathrm{~min}$ was chosen as the optimized contact time. After this time, the removal percentage of the Acid Blue 25 dye fixed and not changed.

\section{The effect of $\mathrm{pH}$}

The $\mathrm{pH}$ quantity participates a notable role in dye adsorption on the various adsorbents [34]. To appraise the effect of $\mathrm{pH}$ on the capacity adsorption, the experiments were directed under fixed experimental conditions, with an initial concentration $30(\mathrm{mg} / \mathrm{L})$, adsorbent quantity $100 \mathrm{mg}$, and contact time $50 \mathrm{~min}$ at temperature $30^{\circ} \mathrm{C}$. The effect of $\mathrm{pH}$ was investigated within the range of 3 to near 9 . The solution $\mathrm{pH}$ was justified with $0.01 \mathrm{M} \mathrm{HCl}$ and $0.01 \mathrm{M} \mathrm{NaOH}$ solutions. Based on the concept of point of zero charge, if the solution $\mathrm{pH}$ is lower than the $\mathrm{pH}_{\mathrm{pzc}}$ (which is 7.1 for CLP) value, it is mostly positively charged, while if the solution $\mathrm{pH}$ is greater than this value, it is mainly negatively charged. The results are shown in Fig. 5d.

The optimum $\mathrm{pH}$ was selected within the range of 3-4. The obtained data suggest that the removal percentage was $\mathrm{pH}$ dependent. The reason is that, more $\mathrm{OH}^{-}$is available at higher $\mathrm{pH}$ and competes with the anionic sulfonic groups (in the structure of Acid Blue 25) for the adsorption of the Acid Blue 25 dye, which results in a reduction in the number of the adsorption sites for the anionic Acid Blue 25 dye molecules [35] because the $\mathrm{OH}^{-}$molecule is smaller than the Acid Blue 25 molecule and is better placed in the adsorbent pores in competition with Acid Blue 25. Also, $\mathrm{H}^{+}$ion is placed on the adsorbent surface thus the Acid Blue 25 anionic dyes attracts the adsorbent and the adsorption percentage increases at lower $\mathrm{pH}$.

\section{The effect of initial concentration}

Another significant variable that can influence the adsorption capacity is the initial concentration of dye or ion [11]. The effect of the initial concentration on the adsorption percentage of the Acid Blue 25 dye was checked by altering the initial concentration from 10 to $70 \mathrm{mg} / \mathrm{L}$, while the next parameters were as pursues: adsorbent dosage $100 \mathrm{mg}$, temperature $30{ }^{\circ} \mathrm{C}$, solution $\mathrm{pH} 3-4$, and contact time $50 \mathrm{~min}$ [36]. The results are shown in Fig. 6a and b. According to these data, the adsorption percentage (\% removal) declines with the initial concentration elevation, but the adsorption capacity, $q_{e}(\mathrm{mg} / \mathrm{g})$, grows with increasing the initial concentration. The maximum adsorption percentage happened almost at the initial concentration of 10 (mg/L). Investigating the absorption capacity at different temperatures indicated that the maximum absorption capacity occurred at temperature of $30^{\circ} \mathrm{C}$ (Fig. 6b).

\section{Adsorption isotherms}

Adsorption isotherms are necessary for explaining the interaction that occurs between the adsorbent and the adsorbate, and are also critical in optimizing the usage of an adsorbent. Various isotherm equations are existing, but two major of them were utilized to represent the equilibrium data of this study, one Langmuir isotherm and another Freundlich model. Langmuir monolayer
Fig. 6 The effect of initial concentration on Acid Blue 25 adsorption percentage under optimum conditions (a); the effect of initial concentration on the desired dye adsorption capacity, $q$, under the optimum conditions at different temperatures $(\mathbf{b})$
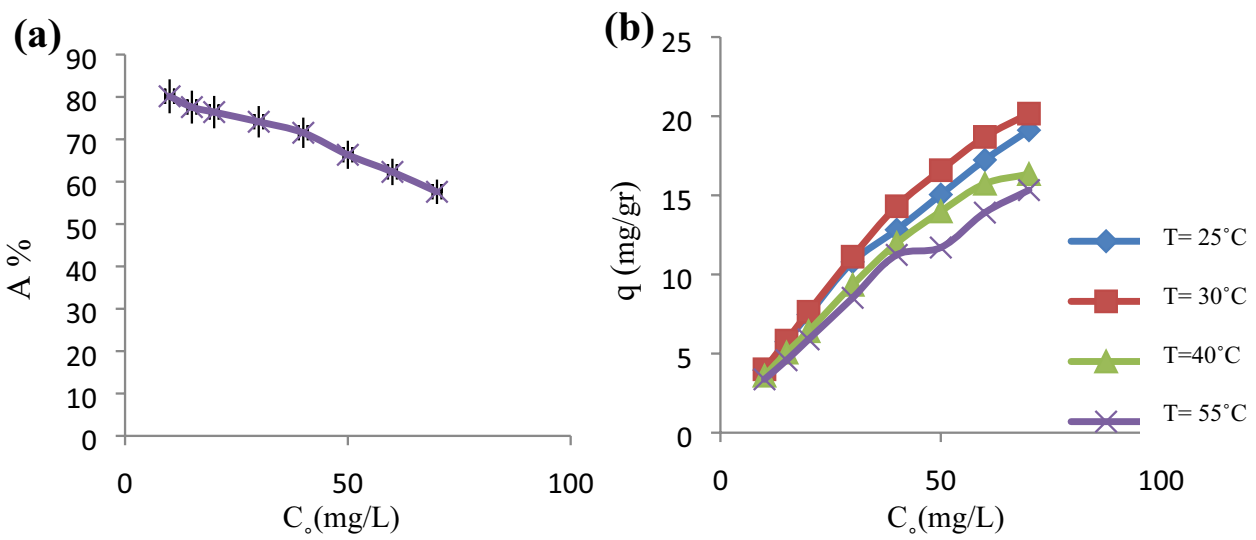
adsorption has a reasonable theoretical basis which gives it a broad application [37]. Based on the statistical mechanical approach and using canonical partition function for a sample of ideal lattice gas (monolayer ideal gas on the solid surface), the molecular chemical potential, $\mu_{\mathrm{ad}}$, of an adsorbed gas molecule was obtained as

$\mu_{\mathrm{ad}}=k T\left(\frac{\theta}{(1-\theta) q}\right)$,

where $\theta$ is the coverage fraction of the solid surface and $q$ is molecular partition function of the adsorbed molecule, $T$ is temperature in Kelvin and $k$ is Boltzmann constant. At equilibrium between the adsorbent phase and the gas phase, we have [38]

$\mu_{\mathrm{ad}}=\mu_{g}=\mu_{g}^{\circ}(T)+k T \ln \left(\frac{P}{P^{\circ}}\right)$.

So,

$k T\left(\frac{\theta}{(1-\theta) q}\right)=\mu_{g}^{\circ}(T)+k T \ln \left(\frac{P}{P^{\circ}}\right)$

Or,

$\left(\frac{\theta}{1-\theta}\right) \frac{1}{P}=\frac{1}{P^{\circ}} q e^{\mu_{0(g) / k T}}$.

The components in the right hand of Eq. (6) are only temperature dependent and so can be considered as a constant, $K(T)$, (or $K_{L}$ ) at constant temperature.

Therefore,

$\left(\frac{\theta}{1-\theta}\right)=K(T)=K_{L} P$,

which lead to the well-known Langmuir adsorption isotherm [39].

$\theta(P, T)=\frac{K_{L} P}{1+K_{L} P}$,

By analogy, we may use the above equation the adsorption of the considered adsorbate from the solution phases onto the solid surface.

For Acid Blue 25, adsorption onto the Chicory leaf powder (CLP) surfaces, we can propose the below simple mechanism [40]:

$\mathrm{AB}+\mathrm{S} \rightleftharpoons \mathrm{ABS}$

With the equilibrium constant, $K$, (Eq. 10)

$K=\frac{[\mathrm{ABS}]}{[\mathrm{AB}][\mathrm{S}]}$,

[ABS] is the number of occupied sites per unit area of the adsorption surface, $[\mathrm{AB}]$ is the concentration of the adsorption in the solution phase and [S] is the number of unoccupied site per unit area of the adsorbent surface. By analogy with the gas adsorption onto the solid surface (equilibrium), we can assume that the $K$ constant in Eq. (10) can be written as [41]

$K=K(T)=K_{L}=\frac{1}{[\mathrm{AB}]^{\circ}} q_{\mathrm{ABS}} e^{\mu_{\circ} / k T,}$

where $[\mathrm{AB}]^{\circ}$ is the standard concentration, $q_{\mathrm{ABS}}$ is the molecular partition function of ABS and $\mu$ is the molecular standard chemical potential of $\mathrm{AB}$ in the solution phase. Based on the values of $K\left(K_{L}\right)$ and its dependent on the temperature, one can estimate the values of thermodynamic function of the adsorption process $\left(\Delta G_{\mathrm{ad}}^{\circ}, \Delta H_{\mathrm{ad}}^{\circ}\right.$ and $\left.\Delta S_{\mathrm{ad}}^{\circ}\right)$. By analogy, Eq. (8) at existing situation can be written as:

$\theta=\frac{K_{L} C}{1+K_{L} C}$,

where $C_{e}$ is the equilibrium concentration of the sorbate in the solution phase. By taking $=\frac{q}{q_{m}}$, we obtain the linear Langmuir equation [42-44]:

$\frac{1}{q_{e}}=\frac{1}{q_{m}}+\left(\frac{1}{q_{m} K_{L}}\right) \frac{1}{C_{e}}$ linear Langmuir isotherm equation,

$\log q_{e}=\log K_{F}+\frac{1}{n} \log C_{e}$ linear Freundlich isotherm equation,

where $q_{e}(\mathrm{mg} / \mathrm{g})$ is the value of adsorbed dye $(\mathrm{mg})$ per unit mass $(\mathrm{g})$ of the adsorbent at equilibrium; $C_{e}(\mathrm{mg} / \mathrm{L})$ denotes the equilibrium concentration; $q_{m}(\mathrm{mg} / \mathrm{g})$ shows the largest adsorption capacity supported by the Langmuir adsorption; $K_{L}(\mathrm{~L} / \mathrm{mg})$ is the equilibrium constant of the Langmuir isotherm; $\mathrm{n}$ and $K_{F}(\mathrm{mg} / \mathrm{g})(\mathrm{L} / \mathrm{mg})^{1 / n}$ illustrate Freundlich constants affiliate to the adsorption intensity and adsorption capacity by the adsorbent, respectively. To attain the Langmuir isotherm parameters, applying the experimental results, the plot of $\frac{1}{q_{e}}$ was drawn versus $\frac{1}{C_{e}}$. Based on Eq. (13), the slope and the intercept of the plot are $\frac{1}{q_{m} K_{L}}$ and $\frac{1}{q_{m}}$, respectively, enabling us to compute the values of $q_{m}$ and $K_{L}$. The Langmuir linear equation and the Freundlich linear equation for the studied dye removal are plotted in Fig. $7 \mathrm{a}$ and b, respectively. The values of $K_{F}$ and $n$ can be derived from the slope $\left(\frac{1}{n}\right)$ and the intercept $\left(\log K_{F}\right)$ from the linear Freundlich equation. The calculated values of the Langmuir and Freundlich parameters based on the outcomes of this study are represented in Table 1. The maximum adsorption capacity $\left(q_{m}\right)$ is $22.222 \mathrm{mg} / \mathrm{g}$ for the Acid Blue 25 dye onto the CLP, Although this value is not high but it can be reliable enough, because it is near the values of some bio adsorbent like References [24, 46]. In the Table 2, the maximum 
Fig. 7 The linear Langmuir isotherm (a), the linear Freundlich isotherm (b), for removing Acid Blue 25 by CLP adsorbent at $298 \mathrm{~K}$

Table 1 Parameters of Freundlich and Langmuir isotherms at $298 \mathrm{~K}$

Table 2 The adsorption of Acid Blue 25 on various adsorbent under different conditions
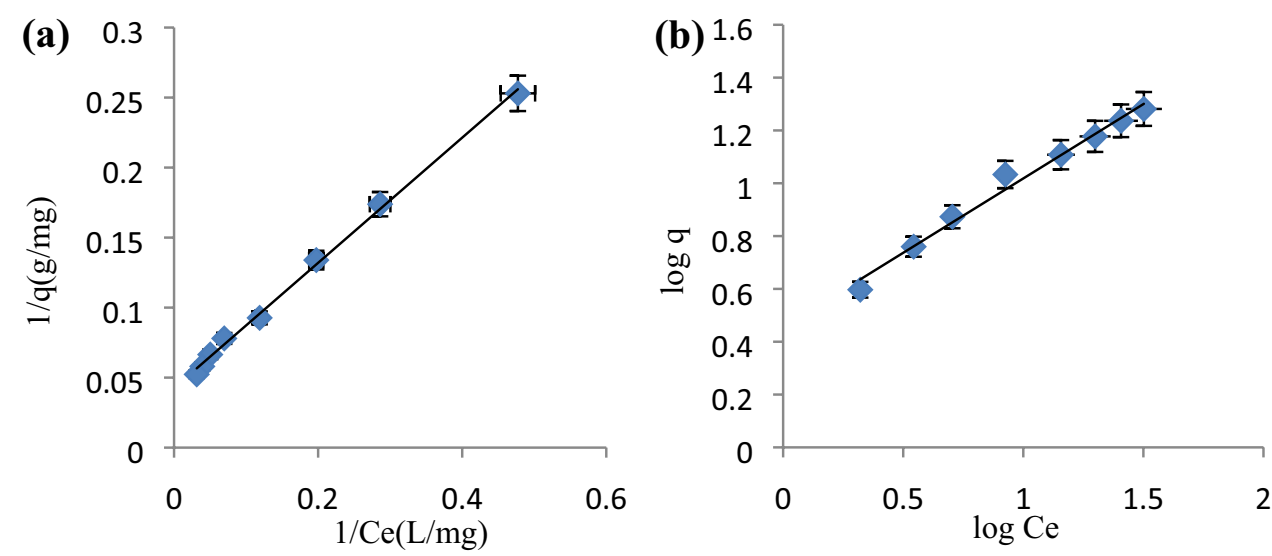

\begin{tabular}{llllllll}
\hline Dye & Freundlich model & & & & \multicolumn{4}{l}{ Langmuir model } \\
\cline { 2 - 3 } & $K_{F}\left(\mathrm{mg}^{1-(1 / n)} \mathrm{L}^{1 / n} \mathrm{~g}^{-1}\right)$ & $n$ & $R^{2}$ & & $K_{L}(\mathrm{~L} / \mathrm{mg})$ & $q_{m}(\mathrm{mg} / \mathrm{g})$ & $R^{2}$ \\
\hline Acid Blue 25 & 3.0974 & 1.867 & 0.986 & 0.112 & 22.222 & 0.997 \\
\hline
\end{tabular}

\begin{tabular}{lll}
\hline Absorbent & $q_{m}(\mathrm{mg} / \mathrm{g})$ & Number of references \\
\hline Calcined diatomite & 9.41 & {$[62]$} \\
Raw diatomite & 21.41 & {$[62]$} \\
Chicory leaf powder & 22.22 & This study \\
Base-treated Shorea dasyphylla sawdust & 24.4 & {$[19]$} \\
Cempedak durian peel & 26.62 & {$[32]$} \\
Phosphoric acid treated rubber leaf powder & 28.09 & {$[64]$} \\
Soya bean waste & 38.3 & {$[11]$} \\
Azolla pinnata & 50.5 & {$[11]$} \\
Quaternized kenaf core fiber & 303.03 & {$[63]$} \\
Crosslinked chitosan beads & 443.3 & {$[2]$} \\
\hline
\end{tabular}

adsorption capacity of Acid Blue 25 on Chicory leaf nanopowder was compared with some other bio adsorbent.

\section{Adsorption thermodynamics}

Thermodynamic quantities can specify the spontaneity and feasibility of the adsorption procedure. Standard Gibbs freeenergy change $\left(\Delta G^{\circ}\right)$, standard enthalpy change $\left(\Delta H^{\circ}\right)$, and standard entropy change $\left(\Delta S^{\circ}\right)$ can be evaluated as follows [45]:

$\Delta G^{\circ}=-R T \operatorname{Ln} K_{C}$,

$\operatorname{Ln} K_{C}=-\frac{\Delta H^{\circ}}{R}\left(\frac{1}{T}\right)+\frac{\Delta S^{\circ}}{R}$,
$\Delta G^{\circ}=\Delta H^{\circ}-T \Delta S^{\circ}$

where $T$ is temperature $(\mathrm{K})$ and $R$ is the ideal gas constant (8.314 J/mol.K). The standard enthalpy change of the studied adsorption $\left(\Delta H_{\text {ad }}^{\circ}\right)$ was calculated from the gradient of the chart of $\operatorname{Ln}\left(K_{c}\right)$ versus $1 / T$, while the standard entropy change $\left(\Delta S_{\text {ad }}^{\circ}\right)$ was computed from the intercept of the plot (Fig. 8a).

Thermodynamic studies were accomplished within the temperature limit of 298-328 K, under the optimized conditions (the initial concentration of Acid Blue 25 was 10 (mg/L), pH 3-4, contact time and adsorbent dosage were $50 \mathrm{~min}$ and $100 \mathrm{mg}$, respectively).

To expand the thermodynamics of the studied adsorption, we may presume a conditional equilibrium constant as follows [46]: 
Fig. 8 The plot of $\operatorname{Ln} K_{C}$ versus $1 / T(\mathbf{a})$, the kinetic investigation of the Acid Blue 25 adsorption capacity at different concentrations (b) at optimum conditions (a)

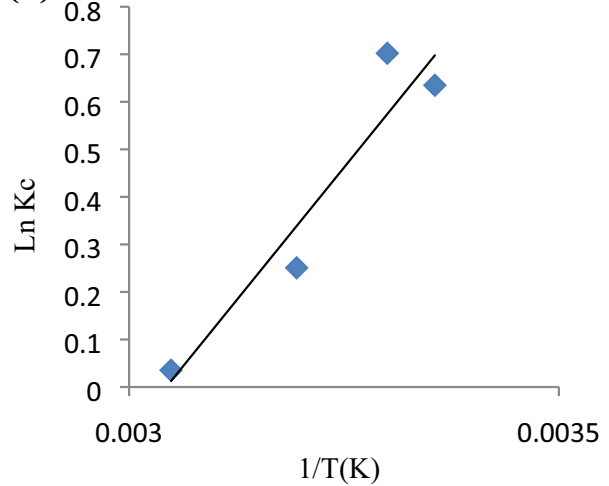

(b)

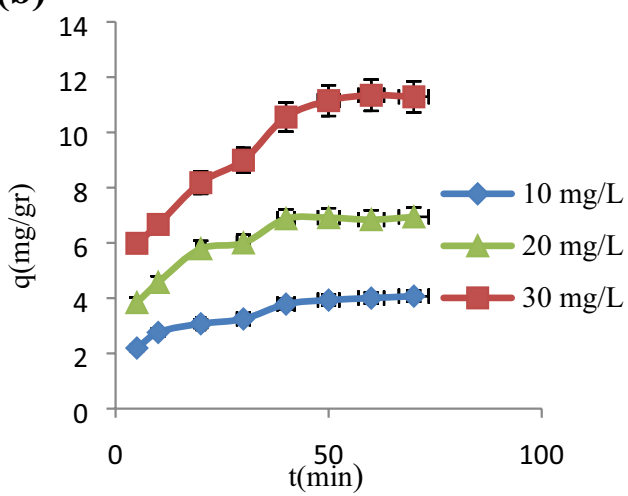

Table 3 Thermodynamic parameters for Acid Blue 25 adsorption onto CLP

\begin{tabular}{lllll}
\hline & $T(\mathrm{~K})$ & $\Delta H^{\circ}(\mathrm{kJ} / \mathrm{mol})$ & $\Delta S^{\circ}(\mathrm{kJ} / \mathrm{mol} \mathrm{K})$ & $\Delta G^{\circ}(\mathrm{kJ} / \mathrm{mol})$ \\
\hline Acid Blue 25 & 298 & -18.566 & -0.056 & -1.729 \\
& 303 & & & -1.446 \\
313 & & & -0.881 \\
& & & -0.034 \\
\hline
\end{tabular}

Sorbate $(\mathrm{aq}) \rightleftharpoons$ Sorbate $(\mathrm{ad})$,

$K_{C}=\frac{\left[\text { sorbate }_{(\mathrm{ad})}\right.}{\left[\text { sorbate }_{(a q)}\right.}=\frac{q_{e}}{C_{e}}$.

This equilibrium constant (Eq. 19) is conditional and not so rigorous from the thermodynamic point of view, but it has been used in major research papers with regards to the adsorption process [47-51]. Based on the conditional $K_{C}$ and the related thermodynamic equations (Eqs. 15-18) and Fig. 8a, one can derive the values of $\Delta H_{\text {ad }}^{\circ}, \Delta G_{\text {ad }}^{\circ}$ and $\Delta S_{\text {ad }}^{\circ}$ associated with Acid Blue 25 adsorption onto CLP as the sorbent. The acquired quantities are represented in Table 3.

In Table 3, the negative quantity of $\Delta H^{\circ}$ indicates the exothermic character of the adsorption process. The free energy change, $\Delta G_{\text {ad }}^{\circ}$, is negative, informing a spontaneous process. The more negative the $\Delta G_{\mathrm{ad}}^{\circ}$, the more spontaneous the adsorption process will be; thus, a higher adsorption capacity is anticipated. Finally, the negative quantity of the entropy change discloses a decrement in randomness at the adsorbate/adsorbent interface during the adsorption process [52].

\section{Adsorption kinetics}

In this research, the kinetic empirical parameters were evaluated via the vastly applied pseudo-first-order and pseudo-second-order models, which are usually defined as follows [53-56]:

$\operatorname{Ln}\left(q_{e}-q_{t}\right)=L n q_{e}-k_{1} t$,

$\frac{t}{q_{t}}=\frac{1}{k_{2} q_{e}^{2}}+\frac{t}{q_{e}}$,

where $q_{e}(\mathrm{mg} / \mathrm{g})$ is the value of the adsorption capacity at equilibrium and $q_{t}(\mathrm{mg} / \mathrm{g})$ represents the value of $q$ at time $t$ (min), $k_{1}(1 / \mathrm{min})$ and $k_{2}$ (g/mg.min) shows the rate constants of the pseudo first-order and the pseudo-second-order adsorption procedures, respectively [57-64]. In this work, the kinetics of the adsorption of Acid Blue 25 dye onto CLP as adsorbent was tested by taking $50 \mathrm{~mL}$ of the dye solution with a concentration $10 \mathrm{mg} / \mathrm{L}$ and the solution was monitored according to the prior method (solution $\mathrm{pH} 3-4$, adsorbent dosage $100 \mathrm{mg}$, for the kinetic experiments at $25^{\circ} \mathrm{C}$ ). The time period was selected within the range of $10-70 \mathrm{~min}$. In Fig. 9a and b, the plots of adsorption kinetic data are drawn and the acquired kinetic data are reported in Table 4.

The adsorption kinetic data of the adsorbed dye were better fitted with pseudo-second-order kinetics where the correlation coefficient was fairly good. Also, the kinetic study was done in optimum conditions at different concentrations, as shown in Fig. 8a. The main results of this investigation showed that the adsorption capacity rose with increasing time for all concentrations. 
Fig. 9 Pseudo-first-order model (a), pseudo-second-order model (b), and the adsorption kinetics of the studied dye onto CLP
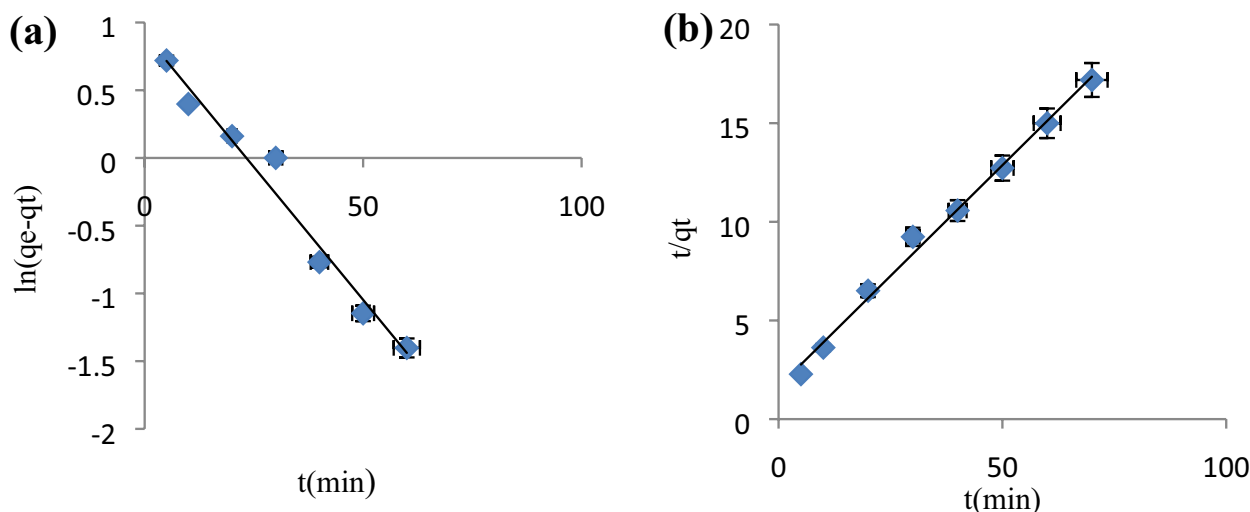

\section{Conclusion}

The results of this research revealed that the prepared CLP as a very fine powder of a native plant has a fairly good ability for removing Acid Blue 25 from aqueous media and acts as a good adsorbent for Acid Blue 25 removal. The optimum condition for removal of the Acid Blue 25 dye onto the CLP adsorption were investigated and reported as: dosage mass $=0.1 \mathrm{~g}, \mathrm{pH}=3-4$, contact time $=50 \mathrm{~min}$, temperature $=30{ }^{\circ} \mathrm{C}$ and initial concentration $=10 \mathrm{mg} / \mathrm{L}$. The result showed that all the parameters influence the removal percentage but the $\mathrm{pH}$ effect was more interesting. The adsorption experimental results showed that the Freundlich and Langmuir isotherms could represent almost all results of this study, but Langmuir isotherm fitted the results better. Furthermore, pseudo-first-order kinetics and pseudo-second-order kinetics were performed to test the kinetic data, where Pseudo-second-order kinetics proved better for representing the kinetic data. The thermodynamic examinations revealed that the studied adsorption process is exothermic and showed a reduction in randomness $\left(\Delta H_{\text {ad }}^{\circ}<0, \Delta S_{\text {ad }}^{\circ}<0\right)$. In addition, the adsorption of Acid Blue 25 dye onto the prepared nano-native powder, under the experimental conditions was spontaneous because of $\Delta G_{\text {ad }}^{\circ}<0$. Finally, given the magnitude of $\Delta H_{\text {ad }}^{\circ}$, we may conclude that the studied adsorption is a physisorption phenomenon. The advantage of using this adsorbent is its simple and low cost preparation method with relatively good results. If other processes are performed on the adsorbent or it becomes functional, the

Table 4 Kinetic parameters for Acid Blue 25 adsorption onto CLP

\begin{tabular}{|c|c|c|c|c|c|}
\hline \multicolumn{3}{|c|}{ Pseudo first-order model } & \multicolumn{3}{|c|}{ Pseudo-second-order model } \\
\hline$q_{e}(\mathrm{mg} / \mathrm{g})$ & $k_{1}(1 / \mathrm{min})$ & $R^{2}$ & $q_{e}(\mathrm{mg} / \mathrm{g})$ & $k_{2}(\mathrm{~g} / \mathrm{mg} \cdot \mathrm{min})$ & $R^{2}$ \\
\hline 2.490 & 0.039 & 0.972 & 4.454 & 0.136 & 0.993 \\
\hline
\end{tabular}

amount of dye removal and its thermodynamic quantities may be improved.

Acknowledgements The authors would like to appreciate Islamic Azad University, Science and Research Branch for all their supports.

Author contribution statement HM Designed and performed experiments, analyzed data and co-wrote the paper. AH Designed experiments and co-wrote the paper. ZK Supervised the research. MM analyzed data.

Open Access This article is licensed under a Creative Commons Attribution 4.0 International License, which permits use, sharing, adaptation, distribution and reproduction in any medium or format, as long as you give appropriate credit to the original author(s) and the source, provide a link to the Creative Commons licence, and indicate if changes were made. The images or other third party material in this article are included in the article's Creative Commons licence, unless indicated otherwise in a credit line to the material. If material is not included in the article's Creative Commons licence and your intended use is not permitted by statutory regulation or exceeds the permitted use, you will need to obtain permission directly from the copyright holder. To view a copy of this licence, visit http://creativecommons.org/licenses/by/4.0/.

\section{References}

1. Rabiul Awuala, Md, Yaitaa, T., Taguchib, T., Shiwakua, H., Suzukia, Sh, Okamoto, Y.: Selective cesium removal from radioactive liquid waste by crown ether immobilized new class conjugate adsorbent. J. Hazard. Mater. 278, 227-235 (2014)

2. Luk, C.J., Yip, J., Yuen, C.M., Kan, C., Lam, K.: A comprehensive study on adsorption behaviour of direct, reactive and acid dyes on crosslinked and non-crosslinked chitosan beads. J. Fiber Bioeng. Inf. 7, 35-52 (2014)

3. Liu, G., Li, Y., Chen, H., Lu, J., Yu, G., Moslang, M., Zhou, Y.: Superior adsorption capacity of functionalised straw adsorbent for dyes and heavy-metal ions. J. Hazard. Mater. 382, 121 (2020)

4. Golkhah, S., Zavvar mousavi, H., Shirkhanloo, H., Khaligh, A.: Removal of $\mathrm{Pb}$ (II) and $\mathrm{Cu}$ (II) ions from aqueous solutions by cadmium sulfide nanoparticles. Int. J. Nanosci. Nanotechnol. 13, 105-117 (2017)

5. Suhas Gupta, V.K.: Application of low-cost adsorbents for dye removal-a review. J. Environ. Manag. 90(8), 2313-2342 (2009)

6. Dbik, A., Bentahar, Sh., El.Khomri, M., El.Messaoudi, N., Lacherai, A.: Adsorption of congo red dye from aqueous solutions 
using tunics of the corm of the saffron. In: Mater. Today-proc, 29 Aug 2019

7. Arora, C., Soni, S., Sahu, S., Mittal, J., Bajpai, P.K.: Iron based metal organic framework for efficient removal of methylene blue dye from industrial waste. J. Mol. Liq. 284, 343-352 (2019)

8. Crini, G.: Non-conventional low-cost adsorbents for dye removal: a review. Bioresour. Technol. 97(9), 1061-1085 (2006)

9. Bailey, S.E., Olin, T.J., Bricka, R.M., Adrian, D.D.: A review of potentially low-cost sorbents for heavy metals. Water Res. 33(11), 2469-2479 (1999)

10. Omidi Khaniabadi, Y., Mohammadi, M.J., Shegerd, M., Sadeghi, S., Saeedi, S., Basiri, H.: Removal of congo red dye from aqueous solutions by a low-cost adsorbent: activated carbon prepared from aloe vera leaves shell. Environ. Health Eng. Manag. J. 4(1), 29-35 (2017)

11. Kooh, M.R.R., Dahri, M.K., Lim, L.B., Lim, L.H.: Batch adsorption studies on the removal of Acid Blue 25 from aqueous solution using Azolla pinnata and soya bean waste. Arab. J. Sci. Eng. 41, 2453-2464 (2016)

12. Crini, G., Badot, P.: Application of chitosan a natural aminopolysaccharide for dye removal from aqueous solutions by adsorption processes using batch studies: a review of recent literature. J. Prog. Polym. Sci. 33, 399-447 (2008)

13. Ghodbane, H., Hamdaoui, O.: Decolorization of antraquinonic dye C.I. Acid Blue 25 in aqueous solution by direct UV irradiation, $\mathrm{UV} / \mathrm{H} 2 \mathrm{O} 2$ and UV/Fe(II) processes. Chem. Eng. J. 160, 226-231 (2010)

14. Javad Roustakhiz, J., Teymori Majnabadi, J.: Cultivation of chicory (Cichorium intybus L.), an extremely useful herb. Int. J. Farm. Allied Sci. 6(1), 14-23 (2017)

15. Barcaccia, G., Ghedina, A., Lucchin, M.: Current advances in genomics and breeding of leaf chicory (Cichorium intybus L.). J. Agric. 6(4), 50 (2016)

16. Haghi, Gh, Arshi, R., Ghazian, F., Hosseini, H.: Chemical composition of essential oil of aerial parts of Cichorium intybus L. from Iran. J. Essent. Oil Bear. Plants 15(2), 213-216 (2012)

17. Rajabi Gol, N., Zhiani Noghani, R., Chamsaz, M.: A comparative study of the chemical composition and antioxidant activities of roots, seeds and aerial parts of chicory (Cichorium intybus L.). Int. J. Biosci. 5(12), 250-257 (2014)

18. Chandra, S., Kumar, M., Dwivedi, P., Arti, K.: Studies on industrial importance and medicinal value of chicory plant (Cichorium intybus L.). Int. J. Adv. Res. 4, 1060-1071 (2016)

19. Megat Hanafiah, M.A.K., Wan Ngah, W.S., Zolkafly, ShH, Teong, LCh., AbdulMajid, Z.A.: Acid Blue 25 adsorption on base treated Shorea dasyphylla sawdust: kinetic, isotherm, thermodynamic and spectroscopic analysis. J. Environ. Sci. 24(2), 261-268 (2012)

20. Rabiul Awual, Md: Assessing of lead (III) capturing from contaminated wastewater using ligand doped conjugate adsorbent. Chem. Eng. J. 289, 65-73 (2016)

21. Rabiul Awual, M., Khraisheh, M., Alharthi, N.H., Luqman, M., Islam, A., Rezaul Karim, M., Rahman, M.M., Abdul Khaleque, Md: Efficient detection and adsorption of cadmium (II) ions using innovative nanocomposite materials. Chem. Eng. J. 343, 118-127 (2018)

22. Ebrahimzadeh Rajaei, G., Aghaie, H., Zare, K., Aghaie, M.: Adsorption of $\mathrm{Ni}$ (II) and Cd (II) ions from aqueous solutions by modified surface of Typha latifolia L. root, as an economical adsorbent. J. Phys. Theor. Chem. 9(3), 137-147 (2012)

23. Stafiej, A., Pyrzynska, K.: Adsorption of heavy metal ions with carbon nanotubes. Sep. Purif. Technol. 58(1), 49-52 (2007)

24. Nahid Pourreza, N., Naghdi, T.: Removal and separation of neutral red from water samples by adsorption on ACID-TREATED SAWDUST. Fresenius Environ. Bull. 20(11), 3076-3080 (2011)
25. Robati, D., Mirza, B., Rajabi, M., Moradi, O., Tyagi, I., Agarwal, S., Gupta, V.K.: Removal of hazardous dyes-BR 12 and methyl orange using graphene oxide as an adsorbent from aqueous phase. Chem. Eng. J. 284, 687-697 (2016)

26. Lampke, T., Wielage, B.: Surface characterization of flax, hemp and cellulose fibers; surface properties and the water uptake behavior. Polym. Compos. 23, 872-894 (2002)

27. Forziati, F.H., Brownell, R.M., Hunt, C.M.: Surface areas of cottons and modified cottons before and after swelling as determined by nitrogen sorption. J. Res. Natl. Bur. Stand. 50, 139-145 (1953)

28. Rabiul Awual, Md: Innovative composite material for efficient and highly selective $\mathrm{Pb}(\mathrm{II})$ ion capturing from wastewater. J. Mol. Liq. 284, 502-510 (2019)

29. Gharbani, P., Mehrizad, A., Jafarpour, I.: Adsorption of penicillin by decaffeinated tea waste. Polish J. Chem. Technol. 17(3), 95-99 (2015)

30. Mehrizad, A., Zare, K., Dashti Khavidaki, H., Dastmalchi, S., Aghaie, H., Gharbani, P.: Kinetic and thermodynamic studies of adsorption of 4-chloro-2-nitrophenol on nano-Ti02. J. Phys. Theor. Chem. 8(1), 33-38 (2011)

31. Yousef, R.I., El-Eswed, B., Ala'a, H.: Adsorption characteristics of natural zeolites as solid adsorbents for phenol removal from aqueous solutions kinetics, mechanism, and thermodynamics studies. Chem. Eng. J. 171, 1143-1149 (2011)

32. Dahri, M.K., Lim, L.B.L., Priyantha, N., Chan, C.M.: Removal of Acid Blue 25 using Cempedak Durian peel from aqueous medium: isotherm, kinetics and thermodynamics studies. Int. Food Res. J. 23(3), 1154-1163 (2016)

33. Lee, S., Kim, D.: Enhanced adsorptive removal of hydrogen sulfide from gas stream with zinciron hydroxide at room temperature. Chem. Eng. J. 363, 43-48 (2019)

34. Khavidaki, H.D., Fekri, M.H.: Removing thallium (I) ion from aqueous solutions using modified $\mathrm{ZnO}$ nanopowder. J. Adv. Chem. 11(7), 3777-3788 (2015)

35. Jiménez-Reyes, M., Solache-Ríos, M.: Sorption behavior of fluoride ions from aqueous solutions by hydroxyapatite. J. Hazard. Mater. 180(1-3), 297-302 (2010)

36. Sarkar, K., Lal Banerjee, S., Kundu, P.P.: Removal of anionic dye in acid solution by self crosslinked insoluble dendronized chitosan. Hydrol. Current Res. 3, 3 (2012)

37. Zhang, Ch., Kaluvan, S., Zhang, H., Wang, G., Zuo, L.: A study on the Langmuir adsorption for quartz crystal resonator based low pressure $\mathrm{CO}_{2}$ gas sensor. Measurement 124, 286-290 (2018)

38. Yang, Y., Liu, Sh, Zhao, W., Wang, L.: Intrinsic relationship between Langmuir sorption volume and pressure for coal: experimental and thermodynamic modeling study. Fuel 241, 105-117 (2019)

39. Li, Y., Li, Q., Wu, C., Luo, X., Yu, X., Chen, M.: The inappropriate application of the regression Langmuir $Q_{\mathrm{m}}$ for adsorption capacity comparison. Sci. Total Environ. 699, 134222 (2019)

40. Jun, B.M., Hwang, H.S., Heo, J., Jang, M.: Removal of selected endocrine-disrupting compounds using Al-based metal organic framework: performance and mechanism of competitive adsorption. J. Ind. Eng. Chem. 79, 345-352 (2019)

41. Gao, L.Y., Deng, J.H., Huang, G.F., Li, K., Cai, KZh: Relative distribution of $\mathrm{Cd}^{2+}$ adsorption mechanisms on biochars derived from rice straw and sewage sludge. Bioresour. Technol. 272, 114-122 (2019)

42. López-Muñoz, M.J., Arencibia, A., Cerro, L., Pascual, R., Melgar, Á.: Adsorption of $\mathrm{Hg}(\mathrm{II})$ from aqueous solutions using $\mathrm{TiO}_{2}$ and titanate nanotube adsorbents. Appl. Surf. Sci. 367, 91-100 (2016)

43. Mehrizad, A., Gharbani, P.: Optimization of operational variables and kinetic modeling for photocatalytic removal of direct blue 14 from aqueous media by $\mathrm{ZnS}$ nanoparticles. J. Water Health 15(6), 955-965 (2017) 
44. Saadi, R., Saadi, Z., Fazaeli, R., Fard, N.E.: Monolayer and multilayer adsorption isotherm models for sorption from aqueous media. Korean J. Chem. Eng. 32(5), 787-799 (2015)

45. Haghdoost, G., Aghaie, H.: Method for the removal of piumbum (II) ion from aqueous solutions by corn cobas a natural adsorbent and from the view point thermodynamics. Orient. J. Chem. 32(3), 1485-1492 (2016)

46. Ali, R., Hamad, H., Hussein, M.M., Malash, G.F.: Potential of using green adsorbent of heavy metal removal from aqueous solutions: adsorption kinetics, isotherm, thermodynamic, mechanism and economic analysis. Ecol. Eng. 91, 317-332 (2016)

47. Dawood, S., Kanti Sen, T.: Removal of anionic dye congo red from aqueous solution by raw pine and acid-treated pine cone powder as adsorbent: equilibrium, thermodynamic, kinetics, mechanism and process design. Water Res. 46, 1933-1946 (2012)

48. Amin, M.T., Alazba, A.A., Shafiq, M.: Adsorptive removal of reactive black 5 from wastewater using bentonite clay: isotherms. Kinet. Thermodyn. Sustain. 7, 15302-15318 (2015)

49. Guo, X., Wang, J.: Comparison of linearization methods for modeling the Langmuir adsorption isotherm. J. Mol. Liquids (2019). https://doi.org/10.1016/j.molliq.2019.111850

50. Xiao, P., Wang, P., Li, H., Li, Q., Shi, Y.: New insights into bisphenols removal by nitrogen-rich nanocarbons: synergistic effect between adsorption and oxidative degradation. J. Hazard. Mater. 345, 123-130 (2018)

51. Song, W., Ge, P., Ke, Q., Sun, Y., Chen, F., Wang, H., Shi, Y., Wu, X.-L., Lin, H., Chen, J., Shen, C.: Insight into the mechanisms for hexavalent chromium reduction and sulfisoxazale degradation catalyzed by graphitic carbon nitride: the Yin and Yang in the photo-assisted process. Chemosphere 221, 166-174 (2019)

52. Li, H., Zhang, D., Han, X., Xing, B.: Adsorption of antibiotic ciprofloxacin on carbon nanotubes: $\mathrm{pH}$ dependence and thermodynamics. Chemosphere 95, 150-155 (2014)

53. Simonin, J.P.: On the comparison of pseudo-first order and pseudo-second order rate laws in the modeling of adsorption kinetics. Chem. Eng. J. 300, 254-263 (2016)

54. Wang, F., Sun, W., Pan, W., Xu, N.: Adsorption of sulfamethoxazole and $17 \beta$-estradiol by carbon nanotubes $/ \mathrm{CoFe}_{2} \mathrm{O}_{4}$ composites. Chem. Eng. J. 274, 17-29 (2015)

55. Zhang, B., Shi, W., Yu, Sh, Zhu, Y.: Adsorption of anion polyacrylamide from aqueous solution by polytetrafluoroethylene (PTFE) membrance as an adsorbent: kinetic and Isotherm studies. J. Colliod Interface Sci. 544, 303-311 (2019)
56. Zare, K., Sadegh, H., Shahryari-Ghoshekandi, R., Maazinejad, B., Ali, V., Tyagi, I., Agarwal, S., Gupta, V.K.: Enhanced removal of toxic congo red dye using multi walled carbon nanotubes: kinetic, equilibrium studies and its comparison with other adsorbents. J. Mol. Liq. 212, 266-271 (2015)

57. Shahryari-Ghoshekandi, R., Sadegh, H.: Kinetic study of the adsorption of synthetic dyes on graphene surfaces. Jordan J. Chem. 9(4), 267-278 (2014)

58. Dandil, S., Sahbaz, D.A., Acikgoz, C.: Adsorption of Cu (II) ions onto crosslinked chitosan/waste active sludge char (WASC) beands: kinetic, equilibrium, and thermodynamic study. Int. J. Biol. Macromol. 136, 668-675 (2019)

59. De Castro, M.L., Abad, M.L., Sumalinog, D.A., Abarca, R.R., de Luna, M.D.: Adsorption of methylene blue dye and $\mathrm{Cu}$ (II) ions on EDTA-modified bentonite: isotherm, kinetic and thermodynamic studies. Sustain. Environ. Res. 28(5), 197-205 (2018)

60. Konicki, W., Aleksandrzak, M., Moszyński, D., Mijowska, E.: Adsorption of anionic azo-dyes from aqueous solutions onto graphene oxide: equilibrium, kinetic and thermodynamic studies. J. Colloid Interface Sci. 496, 188-200 (2017)

61. Haghighizadeh, M., Zare, K., Aghiie, H., Monajjemi. M.: Kinetic and thermodynamic study of $\mathrm{Co}^{2+}$ and $\mathrm{Pb}^{2+}$ ions adsorption onto chicory leaves powder as a native plant sorbent. Phys. Chem. Indian J. 13(2), 1-11 (2018)

62. Badii, Kh, Doulati Ardejani, F., Aziz Saberi, M., Yousefi Limaee, N., Shafaei, S.Z.: Adsorption of Acid Blue 25 dye on diatomite in aqueous solutions. Ind. J. Chem. Technol. 17, 7-16 (2010)

63. Idan, I.J., Abdullah, L.C., Choong, T.S.Y., Jamil, S.N.: Equilibrium, kinetics and thermodynamic adsorption studies of acid dyes on adsorbent developed from kenaf core fiber. Adsorpt. Sci. Technol. 36, 694-712 (2018)

64. Khalid, Kh, Wan Ngah, W.S., Megat Hanafiah, A.K.M., Nur Malek, S.A., Siti Khazaai, N.M.: Acid Blue 25 adsorption onto phosphoric acid treated rubber leaf powder. Am. J. Environ. Eng. 5(3), 19-25 (2015)

Publisher's Note Springer Nature remains neutral with regard to jurisdictional claims in published maps and institutional affiliations. 